\title{
Better Prognosis in Newborns with Trisomy 13 Who Received Intensive Treatments: A Retrospective Study of 16 Patients
}

\author{
Keiko Tsukada • George Imataka • Hiroshi Suzumura • \\ Osamu Arisaka
}

Published online: 10 April 2012

(c) The Author(s) 2012. This article is published with open access at Springerlink.com

\begin{abstract}
Intensive treatment for newborns with trisomy 13 is controversial because of their lethal prognosis. We report the better life prognosis of patients with trisomy 13 who received intensive treatment. At our hospital, we provided an intensive management to such patients including resuscitation and surgical procedures as required. Herein, we present the results of a retrospective study (1989-2010) of 16 trisomy 13 cases who received an intensive treatment. None was diagnosed to have trisomy 13 before birth; 9 were delivered by $\mathrm{C}$-section and oxygen was administered to all patients during postpartum resuscitation. Mechanical ventilation was used in 9 patients after tracheal intubation and tracheotomy was performed in 2 patients when withdrawing of extubation was difficult. Regarding prognosis, 9 patients died, 3 were referred to another hospital, and 4 were discharged from the hospital. Four and 7 patients died within 7 and 30 days after birth, respectively. Nine patients survived for $>1$ month, 7 for $>180$ days, and 5 for $>3$ years. Median survival for 16 patients was 733 days. The patients who received intensive treatments survived longer compared to the previous data. This study provides useful information concerning genetic counseling, especially from an ethical point of view, before providing intensive management to newborns with trisomy 13.
\end{abstract}

Keywords Trisomy 13 - Prognosis - Intensive treatment · Survival $\cdot$ Natural history

K. Tsukada $\cdot$ G. Imataka $(\bowtie) \cdot$ H. Suzumura $\cdot$ O. Arisaka Department of Pediatrics, Dokkyo Medical University School of Medicine, Kitakobayashi 880, Mibu, Tochigi 321-0293, Japan e-mail: geo@dokkyomed.ac.jp

\section{Introduction}

Trisomy 13, first reported by Patau et al. [1], is the third common trisomy in live born infants. It is clinically associated with various anomalies, found in $80 \%$, of cardiac and circulatory systems, such as mainly ventricular septal defect, patent ductus arteriosus, auricular septal defect and 60-80\% with cleft lip and/or palate of mouth, and $50 \%$ or more with the following: central nervous system with holoprosencephaly, hearing system with apparent deafness, cranium with microcephaly with sloping forehead, eyes with microphthalmia and colobomata of iris, retinal dysplasia, abnormal auricle helices, skin with capillary hemangioma of forehead, distal palmar axial triadii, simian crease, hypoconvex narrow fingernails, flexion of fingers with or without overlapping and camptodactyly, polydacyly of hand, skeletal of thin posterior ribs and hypoplasia of pelvis, males with cryptorchidism/abnormal scrotum and females with bicornuate uterus and another malformation accompanied by severe psychomotor disorder [2, 3]. The prevalence studies from Denmark and United Kingdom reported birth prevalence in live born of trisomy 13 as $\sim 1$ in 20,000 to 1 in 29,000 [4, 5]. The Hawaiian study reported prevalence at birth of trisomy 13 as 1 in 12,048 in live born infants [6]. Jones described that the incidence was $\sim 1$ in 5,000 births [3]. Generally, natural prevalence of delivery at birth of trisomy 13 is between 1 in 5,000 and 1 in 29,000 , which is the third most common autosomal trisomy in newborns following trisomy 21 and trisomy 18 .

The approach to the management policy of a third-trimester fetus and infant with trisomy 13 and 18 is quite complicated, and the existing literature is controversial. The principal reason for the complexity surrounding decision making in the care of infants with trisomy 13 relates to high neonatal and infant mortality in both conditions [7, 8]. 
Avoidance of delivery by cesarean section when a fetus is known to have trisomy 13 appears to be the trend in Denmark as shown by obstetrics literature. There was strong consensus among physicians working in perinatal medicine toward abortion for social reasons or because of abnormal prenatal diagnostic results that abortion is acceptable until week 21 in the case of trisomy 13 [9]. Moreover, there tends to be extremely negative information about survival of trisomy 13. It is important to acknowledge that the prognosis is lethal. Approximately, $50 \%$ of infants with trisomy 13 will live longer than a week and $5-10 \%$ of infants will live past 1 year $[7,8]$. Tradition, as reflected in the pediatric literature, also indicates a nonintervention approach in the newborn management of trisomy 13. Bos et al. [10] summarized these issues, arguing that early diagnosis was very important so that surgery could be withheld. The important issues that emerge in the counseling and management of newborn infants with trisomy 13 are high infant mortality. Survivors have severe mental retardation, often seizures, and fail to thrive. So that surgical or orthopedic corrective procedures should be withheld in early infancy to await the outcome of the first few months [3].

In Japan, the policies for the treatment of chromosomal anomalies including trisomy 13 and 18 with poor long-term prognoses are determined based on either of two controversial concepts: (i) the provision of thorough love and care while avoiding excessive intensive treatment; or (ii) the provision of active intensive treatment including resuscitation and surgery according to the clinical conditions of an infant and in accordance with the wishes of the infant's parents [11, 12]. The most important problems in this argument were that there was no evidence about the improvement of prognosis of trisomy 13 treated at the Neonatal Intensive Care Unit (NICU) of Dokkyo Medical University Hospital. In the same context, Kosho et al. [11, 13] investigated the prognosis of intensive treatments in 24 Japanese patients with trisomy 18 at NICU. This report argued better prognosis of trisomy 18 through treatment at NICU based on improved survival period, and the data provide helpful guidelines for clinicians by offering the best information on treatment options for families of patients with trisomy 18 . However, there is still a lack of precise data concerning the clinical details and prognosis regarding intensive treatments of patient with trisomy 13.

The NICU at the Dokkyo Medical University Hospital provides the intensive treatments including resuscitation of intratracheal intubation, respiratory support, and some kind of surgery for trisomy 13 and 18, if informed consent is obtained from the family after counseling. At NICU, the five tentative treatment policies for trisomy 13 and 18 with poor long-term prognoses of survival are as follows: (1) The treatment policy is determined without relation with trisomy 13 and 18, and is determined after the pathology, treatment options and risks involved have been explained to the parents; (2) The actual initial treatment with resuscitation and medical therapy after delivery are provided to neonates who have ordinary cases, and surgical treatment is also not limited; (3) With respect to surgical treatment and resuscitation, even in case of long-term survival; (4) Psychological care for family is regularly provided by clinical psychotherapists; and (5) Management at home is actively discussed if the family wishes for it.

In this study, in order to determine the survival period of trisomy 13 patients who received intensive treatment, we retrospectively analyzed the detailed clinical data of 16 patients with trisomy 13 , admitted to NICU at the Dokkyo Medical University Hospital from 1989 to 2010.

\section{Patients and Methods}

This study comprised 6,230 newborn infants who were hospitalized at the neonatal care unit of Dokkyo University Hospital, Japan during the period of 22 years from 1989 to 2010. Newborn infants presenting with external malformations or organ malformations that were observed during the clinical examinations underwent chromosomal analysis, and 183 patients $(2.94 \%)$ were diagnosed with chromosomal anomalies. Of these, 138 patients $(2.22 \%)$ were diagnosed with numerical autosomal aberration. A breakdown of these patients of numerical autosomal aberration shows trisomy 21 in 83 patients $(1.33 \%)$, trisomy 18 in 39 patients $(0.63 \%)$, and trisomy 13 in 16 patients $(0.26 \%)$. Other chromosomal abnormalities were 45 patients $(0.72 \%)$ including 2 patients with trisomy 8 mosaic and 2 patients with 4 p-syndrome and others. In this study, we retrospectively investigated the NICU medical records at our hospital regarding the clinical details of 16 patients with trisomy 13 who received intensive treatment.

\section{Results}

Family History, Ages of the Parents, History of Pregnancy, and Delivery (Table 1)

None of the 16 patients with trisomy 13 had chromosomal abnormalities in their family histories. The age of the mothers ranged from 20 to 42 years (average: 32.9 years) including mothers who were over 35 -years-old for 7 patients and over 40 -years-old for 2 patients. The age of the fathers ranged from 22 to 47 years (average: 33.8 years) including fathers who were over 35 -years-old for 7 patients and over 40-years-old for 3 patients. Regarding the history of previous delivery, 5 patients had parous mothers. In terms of 
Table 1 Family history, age of parents, pregnancy, and delivery regarding 16 patients with trisomy 13

\begin{tabular}{|c|c|c|c|c|c|c|c|c|}
\hline Patients & $\begin{array}{l}\text { Age of parents } \\
\text { (father/mother) }\end{array}$ & $\begin{array}{l}\text { History of } \\
\text { previous } \\
\text { delivery }\end{array}$ & Gender & $\begin{array}{l}\text { Prenatal ultrasonographic } \\
\text { findings }\end{array}$ & $\begin{array}{l}\text { Cesarean } \\
\text { section }\end{array}$ & $\begin{array}{l}\text { Apgar score } \\
(1 \mathrm{~min} / 5 \mathrm{~min})\end{array}$ & $\begin{array}{l}\text { Gestational } \\
\text { age (weeks) }\end{array}$ & $\begin{array}{l}\text { Birth } \\
\text { weight } \\
\text { (g) }\end{array}$ \\
\hline 1 & $31 / 29$ & - & M & Hydrocephalus IUGR & - & $3 / 4$ & 35 & 1,582 \\
\hline 2 & $32 / 32$ & - & $\mathrm{F}$ & $\begin{array}{l}\text { Holoprosencephaly } \\
\text { umbilical hernia severe } \\
\text { IUGR }\end{array}$ & + & $1 / 2$ & 35 & 1,756 \\
\hline 3 & $32 / 31$ & - & M & IUGR & + & $3 / 6$ & 40 & 2,162 \\
\hline 4 & $35 / 42$ & + & M & Hydronephrosis & + & $1 / 3$ & 33 & 3,378 \\
\hline 5 & $41 / 40$ & + & M & IUGR oligoamnios & + & $2 / 5$ & 37 & 2,254 \\
\hline 6 & $22 / 20$ & - & $\mathrm{F}$ & IUGR & - & $6 / 7$ & 37 & 2,237 \\
\hline 7 & $33 / 33$ & - & $\mathrm{F}$ & Hydrocephalus oligoamnios & + & $8 / 9$ & 35 & 2,540 \\
\hline 8 & $30 / 35$ & + & M & - & - & $8 / 9$ & 36 & 2,380 \\
\hline 9 & $34 / 32$ & - & $\mathrm{F}$ & Holoprosencephaly IUGR & + & $1 / 3$ & 36 & 2,784 \\
\hline 10 & $22 / 21$ & - & M & IUGR & - & $8 / 8$ & 37 & 2,342 \\
\hline 11 & $36 / 35$ & - & $\mathrm{F}$ & $\begin{array}{l}\text { Hydrocephalus IUGR } \\
\text { polydactyly origoamnios }\end{array}$ & - & $4 / 9$ & 35 & 1,960 \\
\hline 12 & $29 / 33$ & - & M & Severe IUGR & - & $3 / 7$ & 34 & 1,602 \\
\hline 13 & $39 / 37$ & + & M & Origoamnios & & & & \\
\hline 14 & $36 / 36$ & - & $\mathrm{F}$ & Severe IUGR & - & $8 / 10$ & 37 & 1,746 \\
\hline 15 & $47 / 34$ & + & M & IUGR & - & $4 / 8$ & 39 & 3,366 \\
\hline 16 & $41 / 37$ & - & M & IUGR & + & $3 / 6$ & 35 & 1,950 \\
\hline
\end{tabular}

$M$ male, $F$ female, IUGR intrauterine growth retardation

gender, there were 10 males and 6 females. A definitive prenatal diagnosis of amniotic fluid test for trisomy 13 was not carried out for any of the 16 patients. However, in 15 patients diagnosed with trisomy 13 , some type of abnormality was indicated in the ultrasonography test during the course of pregnancy, such as intrauterine growth retardation in 11 patients and brain malformations in 5 patients. The term of delivery ranged from 33 to 40 gestational weeks (average: 35.9 gestational weeks). Regarding the method of delivery, 9 patients were delivered via a cesarean section and 7 patients were delivered via a spontaneous cephalic delivery. The delivery term for the performance of cesarean section ranged from 33 to 40 gestational weeks (average: 35.8 gestational weeks).

The average of Apgar Score at the time of birth was 4.25 points for $1 \mathrm{~min}$ scores and 6.5 points for $5 \mathrm{~min}$ scores. The birth weight ranged from 1,582 to $3,378 \mathrm{~g}$, with an average weight of $2,243 \mathrm{~g}$. The breakdown includes 7 patients weighing 1,500 to $2,000 \mathrm{~g}, 5$ patients weighing 2,000 to $2,500 \mathrm{~g}, 2$ patients weighing 2,500 to $3,000 \mathrm{~g}$, and 2 patients weighting at least $3,000 \mathrm{~g}$.

\section{Chromosomal Analysis, External Malformations, and Organ Malformations (Table 2)}

The chromosomal karyotypes of all 16 patients were diagnosed using a G-band method. The $r$ karyotypes included full trisomy 13 in 14 patients, mosaic type of trisomy 13 in 1 patient, and Robertsonian type of translocation in 1 patient.

The major external craniofacial malformations included scalp defects in 5 patients for the head and cleft lip and palate in 10 patients for the face; malformation of abdomen included umbilical hernia in 8 patients. Polydactyly was noted in 6 patients for the extremities. Among the major organ malformations, 3 patients had alobar and 1 patient had semilobar type of holoprosencephaly. Dandy-Walker malformation was observed 1 patient and olfactory aplasia and fenestration of the septum pellucidum in 1 patient for the brain. As for the heart, some type of congenital cardiac disorder was observed in all patients. The breakdown includes atrial septal defect in 7 patients, ventricular septal defect in 6 patients, patent ductus arteriosus in 7 patients, coarctation of the aorta in 3 patients, endocardial cushion defect in 2 patients, tetralogy of Fallot (TOF) in 3 patients, and doubleoutlet right ventricle (DORV) in 3 patients. Combined respiratory malformations included congenital hypoplastic lung in 2 cases and congenital tracheal stenosis in 2 cases.

Administration of Oxygen and the Use of Mechanical Ventilation and Surgical Treatment (Table 3)

Signs of acute respiratory failure were observed in 13 patients after birth. To resuscitate, oxygen was administered to all 16 patients. Mechanical ventilators were used 


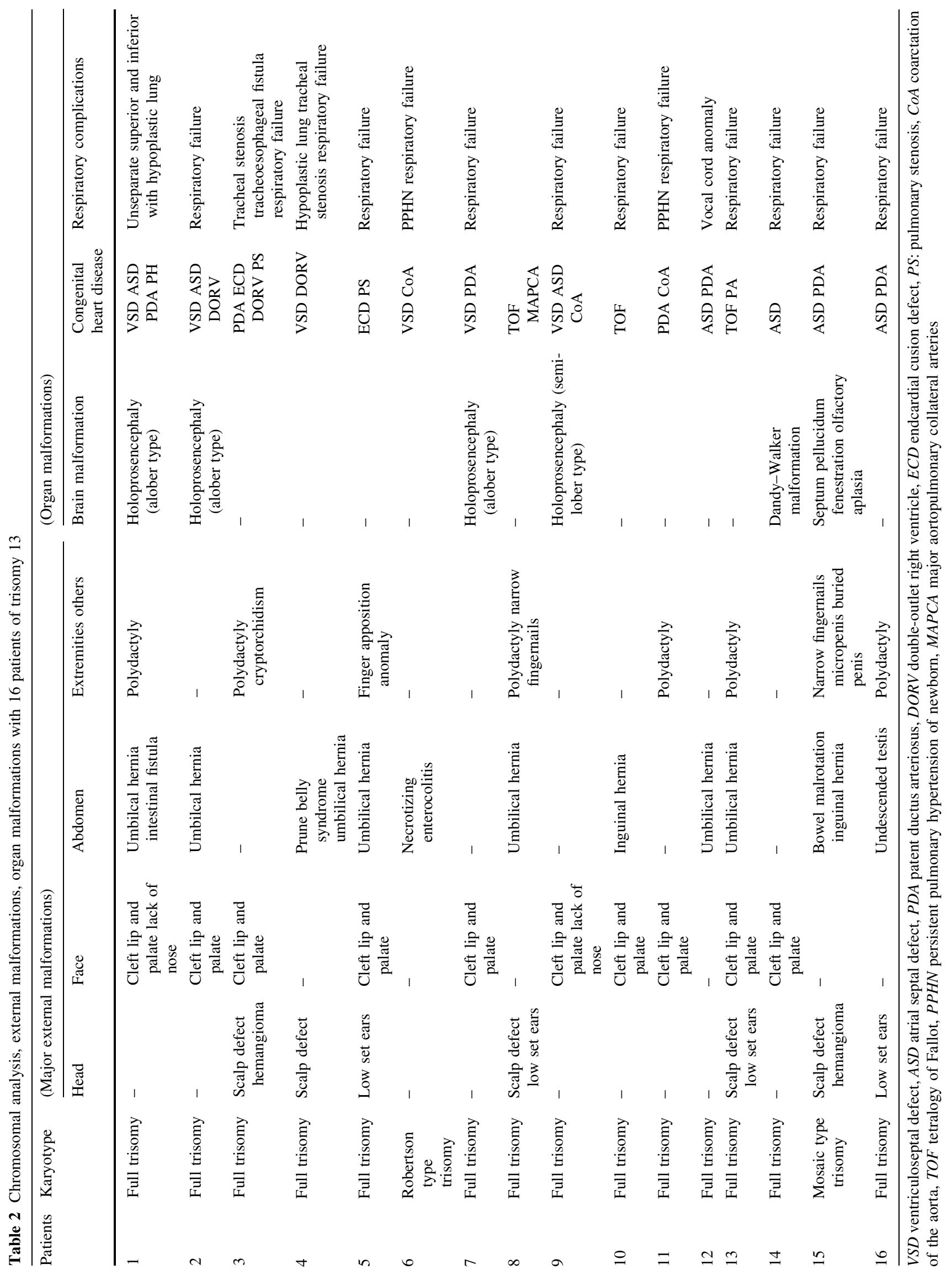


Table 3 Administration of oxygen and the use of mechanical ventilation and surgical treatment, others with 16 patients of trisomy 13

\begin{tabular}{|c|c|c|c|c|c|}
\hline Patients & $\begin{array}{l}\text { Resuscitation } \\
\text { of oxygen }\end{array}$ & $\begin{array}{l}\text { Mechanical } \\
\text { ventilation }\end{array}$ & $\begin{array}{l}\text { Mode of } \\
\text { ventilation }\end{array}$ & Surgical treatment & Others \\
\hline 1 & + & - & - & - & - \\
\hline 2 & + & + & IMV & - & Seizures \\
\hline 3 & + & - & - & - & - \\
\hline 4 & + & + & IMV, HFO & Operation for paracentesis of hydronephrosis & - \\
\hline 5 & + & - & - & - & - \\
\hline 6 & + & - & - & - & - \\
\hline 7 & + & - & - & - & - \\
\hline 8 & + & + & IMV & Operation for umbilical hernia & \\
\hline 9 & + & + & IMV & - & Seizures \\
\hline 10 & + & - & - & - & HOT \\
\hline 11 & + & - & - & $\begin{array}{l}\text { Plastic operation for cleft lip and palate operation } \\
\text { for PDA ligation subcravian method for CoA }\end{array}$ & - \\
\hline 12 & + & + & IMV & - & Seizures \\
\hline 13 & + & + & IMV & Blalock-Taussig operation for TOF & - \\
\hline 14 & + & + & IMV & - & - \\
\hline 15 & + & + & IMV & $\begin{array}{l}\text { Tracheotomy operation for inguinal hernia operation } \\
\text { for buried penis }\end{array}$ & Seizures \\
\hline 16 & + & + & IMV & Tracheotomy & HOT \\
\hline
\end{tabular}

$I M V$ intermittent mandatory ventilation, $H F O$ high frequency oscillation, $H O T$ home oxygen therapy, $P D A$ patent ductus arteriosus, $C o A$ coarctation of the aorta, TOF tetralogy of Fallot

for 9 patients to control acute respiratory failure after tracheal intubation. The tracheal intubation was unsuccessful in 1 patient due to severe tracheal stenosis.

The various types of congenital malformations were observed in all 16 patients with trisomy 13 ; consultations with specialized surgeons were conducted to determine whether surgical treatment would be possible. Due to the difficulty of tube withdrawal after prolonged intubation, tracheotomy was performed for 2 patients. After tracheotomy, respiratory conditions in both patients were stabilized and they were able to survive for long-time period over 7 years. Abdominal operation for umbilical hernia was performed in 1 patient and for inguinal hernia in 1 patient. Plastic operation of the cleft lip and palate was performed in 1 patient in order to improve the cosmetic problem at 210 days of birth before discharge. Cardiac surgery was performed in 2 patients with trisomy 13 . Ligation for patent ductus arteriosus and subclavian methods for coarctation of the aorta were carried out for 1 patient but she was died at 592 days of birth because of respiratory failure. Cardiac operation using Blalock-Taussig method was performed for TOF in 1 patient at 330 days of birth and she has survived for more than 3 years and 3 months now.

Outcomes and Main Cause of Death (Table 4)

In-hospital death at NICU occurred in case of 9 patients, whereas 7 patients were discharged with the condition of homecare. Among them, 3 patients were referred by our hospital to another specialized institution close to the patients' homes for training purpose of homecare nursing at days 349, 251, and 63 after birth. The ages of 4 patients discharged from our hospital to their homes while they were alive were 336, 331, 256, and 204 days after birth. The average of median hospital stay regarding 7 patients who could be discharged including stay in another specialized institute was 256 days after birth. The survival period of the 16 patients with trisomy 13 ranged from death at day 1 (within $24 \mathrm{~h}$ of birth) to 10 years and 1 month (this patient lives until now).

The breakdown includes death at 1st day of birth, within $24 \mathrm{~h}$, for 1 patient $(6.25 \%)$, death within 7 days of birth for 4 patients $(25.00 \%)$, and death within 1 month of birth for 7 patients $(43.75 \%)$. On the other hand, 9 patients survived for more than 1 month $(56.25 \%), 6$ patients survived for more than 1 year $(37.50 \%)$, and 3 patients survived for more than 5 years $(18.75 \%)$. Therefore, the survival rates at ages of 1 day, 1 week, 1 month, 6 months, 1 year, 3 years and 5 years were 93.75, 75.00, $56.25,43.75,37.50,31.25$, and $18.75 \%$, respectively. Median survival time for all 16 patients, both males and females, were 733, 887, and 534 days, respectively.

We also reviewed the data in detail to analyze the main cause of death. Some characteristic trend was recognized as follows: death occurred in 4 patients within 1 week of birth 
Table 4 Outcomes and life prognosis with 16 patients of trisomy 13

\begin{tabular}{|c|c|c|c|c|c|}
\hline Patients & Discharge(days) & $\begin{array}{l}\text { Transfer another } \\
\text { hospital (days) }\end{array}$ & Home care & Survival time (days) & Main cause of death \\
\hline 1 & - & - & - & $12 \mathrm{~h}$ & Respiratory failure due to hypoplastic lung \\
\hline 2 & - & - & - & 1 & DORV \\
\hline 3 & - & - & - & 1 & DORV tracheal stenosis \\
\hline 4 & - & - & - & 2 & DORV \\
\hline 5 & - & - & - & 11 & Heart failure \\
\hline 6 & - & - & - & 14 & PPHN respiratory failure \\
\hline 7 & - & - & - & 21 & Heart failure respiratory failure \\
\hline 8 & - & - & - & 39 & Heart failure \\
\hline 9 & - & - & - & 50 & Heart failure respiratory failure \\
\hline 10 & 204 & - & + & 325 & Bacterial infection \\
\hline 11 & 255 & - & + & 592 (live) & - \\
\hline 12 & 63 & 63 & + & 1186 & Respiratory failure \\
\hline 13 & 349 & 349 & + & 1219 (live) & - \\
\hline 14 & 251 & 251 & + & 1842 (live) & - \\
\hline 15 & 336 & - & + & 2,705 & s/o central apnea \\
\hline 16 & 331 & - & + & 3,713 (live) & - \\
\hline
\end{tabular}

DORV double-outlet right ventricle, $P P H N$ persistent pulmonary hypertension of newborn, s/o suspect of

due to a major organ anomaly; especially, 3 patients had DORV and in 2 of 3 , intubation with ventilation management was performed. On the other hand, 4 of 6 patients from long-survival group (over 365 days, now living) had some kind of surgery that included tracheotomy in 2 patients and cardiac surgery in other 2 patients. Moreover, 5 of 6 patients from long-survival group (over 365 days) had a history of ventilation therapy.

The longest survival time was set at 365 days (Fig. 1) and 1,825 days equal 5 years (Fig. 2) in the Kaplan-Meier

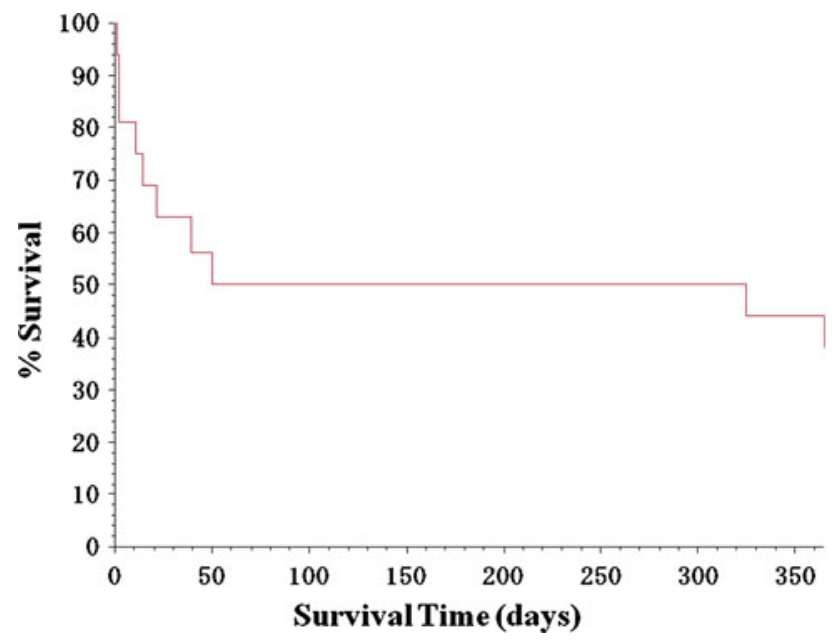

Fig. 1 Kaplan-Meier survival curves. Kaplan-Meier survival curves are shown for patients with trisomy 13 who received treatment at the neonatal intensive care unit (NICU) of Dokkyo Medical University Hospital. The data represent 16 trisomy 13 patients. The vertical and horizontal axes represent \% survival and survival time (days), respectively, setting the longest survival time at 365 days survival curves prepared from the mortality data of all 16 patients with trisomy 13. These Kaplan-Meier survival curves showed mainly two groups: one group that survived for about 2 months and the other group survived for over 365 days.

\section{Discussion}

Among autosomal chromosomal abnormalities, birth is generally believed to be possible in patients of trisomies 21, 18, and 13. Of these, trisomies 18 and 13 are also referred to as fatal chromosomal abnormalities that lead to the development of many severe malformations [14]. Most patients with trisomy 18 and 13 present with severe psychomotor delay, even if they survive for a long period $[4,15,16]$. Historically since the 1980 s, resuscitation and surgical treatments for trisomy 18 and 13 have been discussed both from medical and ethical standpoints, taking into consideration the quality of life for the patients and families, medical and economical issues, and the medical standards in different countries. In Japan, the concept of "no treatments beyond current treatments" as proposed by Nishida and Sakamoto [12] of the Tokyo Women's Medical University has influenced many medical institutions with regard to medical care and management of newborn infants. However, recently, there are few reports of patients with trisomy 13 in Japan who have survived for long periods [17]. Notably, the current problem in Japan is, the primary doctors who tend to patients with trisomy 13 or trisomy 18 provide healthcare by their own medical 


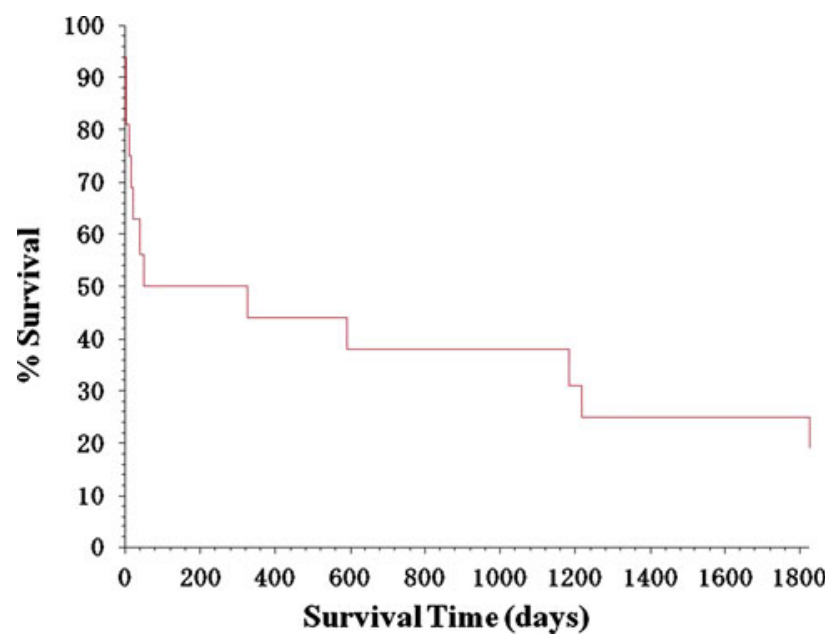

Fig. 2 Kaplan-Meier survival curves. Kaplan-Meier survival curves are shown for patients with trisomy 13 who received treatment at the neonatal intensive care unit (NICU) of Dokkyo Medical University Hospital. The data represent 16 trisomy 13 patients. The vertical and horizontal axes represent \% survival and survival time (days), respectively, setting the longest survival time at 1,825 days

environments and policies, and no discrete guidelines in this concern have been established. Regarding the medical policy of negative intensive treatment performed without the explanation of detailed medical information, a part of support group members with trisomy 18 or trisomy 13 in Japan have expressed a desire for more active intensive treatment after informed consent.

As for the prognoses of trisomy 13 , there is one known report published in 2003 by the American Research Group regarding a large-scale survey of 5,515 cases. According to this report, the average age at the time of death was 10 days, but $5.6 \%$ of the cases survived for more than 1 year [8]. Besides, other long-term survival cases were reported including a 38-year-old adult case of trisomy 13 [18]. There have been several other reports about long-term survivors with trisomy 13 [4, 5, 8, 16, 19]. As summarized in Table 5, our data represent significantly longer median survival periods for the patients with trisomy 13 treated intensively at the NICU.

Of note, two reports have compared between active intensive treatment and non-active treatment with regard to prognosis of trisomy $18[11,14]$ but no such reports are available regarding trisomy 13 . Herein, we present for the first time a study of patients with trisomy 13 who received active intensive treatment and discuss the clinical picture and prognosis. Our data suggest that the patients with trisomy 13 who have survived over 60 days after birth may have a high probability of long-term survival. In the previous report on survival of trisomy 18 patients, those who survived longer than 7 months after birth might have a high probability of long-term survival prognosis [14]. In this study, we should not only consider 9/16 (56.25\%) of patients with trisomy 13 who died in the hospital without discharge but also those $7 / 16(43.75 \%)$ of patients who were discharged or transferred for purpose of homecare. As our data reveal, one of the major causal factors involved in long-term survival of patients with trisomy 13 is whether the provision of active resuscitation should follow immediately after birth, and then the various surgical treatments should be performed in survivors such as tracheotomy and cardiac surgery. Two previous studies reported intensive cardiac management in patients with trisomy 13 or trisomy $18[20,21]$. These studies summarized intensive cardiac management including pharmacological intervention, performed to improve the survival periods in patients with trisomy 13 or trisomy 18 . In our study, two patients underwent cardiac surgery. One surgical procedure involved ligation of patent ductus arteriosus and subclavian methods for coarctation of the aorta, the other was Blalock-Taussig procedure for TOF; and both survived for long periods: 592 days and more than 3 years and 3 months (living until date), respectively. In addition, all 3 patients with DORV died within 2 days of birth, despite that fact that ventilation management was performed in 2 cases.

Table 5 Compared survival rates of trisomy 13 in our study with previously reported

\begin{tabular}{|c|c|c|c|c|c|c|}
\hline Survival time (age) & $\begin{array}{l}\text { Denmark [4] } \\
n=76 \\
\% \text { surviving }\end{array}$ & $\begin{array}{l}\text { England [5] } \\
n=16 \\
\% \text { surviving }\end{array}$ & $\begin{array}{l}\text { Scotland [16] } \\
n=84 \\
\% \text { surviving }\end{array}$ & $\begin{array}{l}\text { Atlanta, USA [8] } \\
n=114 \\
\% \text { surviving }\end{array}$ & $\begin{array}{l}\text { Taiwan [19] } \\
n=28 \\
\% \text { surviving }\end{array}$ & $\begin{array}{l}\text { Japan (our study) } \\
n=16 \\
\% \text { survival }\end{array}$ \\
\hline 1 day & 77 & 69 & 75 & 86 & 89 & 93.75 \\
\hline 7 days & 40 & 38 & 50 & 56 & 61 & 75 \\
\hline 1 month & 23 & 13 & 28 & 30 & 29 & 56.25 \\
\hline 6 months & 10 & 0 & ND & 11 & 7 & 43.75 \\
\hline 1 year & ND & 0 & 3 & 9 & 4 & 37.5 \\
\hline 3 years & ND & 0 & ND & ND & 4 & 31.25 \\
\hline 5 years & ND & 0 & ND & ND & ND & 18.75 \\
\hline Median survival (days) & 2.5 & 4 & 8.5 & 7 & 9 & 733 \\
\hline
\end{tabular}

$N D$ no data 
In conclusion, although our clinical data represent a small number of trisomy 13 patients, we did observe significantly better survival prognosis in the patients who received intensive treatment management. Our clinical results underscore the need to consider obtaining informed consent and counseling from patients' families for the future determinations of treatment policy for trisomy 13 patients.

Acknowledgments This work was supported by three grants: one from Japanese Ministry of Education, Culture, Sports, Science and Technology (MEXT) (Ref. KAKENHI 18790733), second Grantin-Aid for Young Scientists (B), and the Investigator-Initiated Research Grant from Dokkyo Medical University (No. 2005-01-5/ No. 2009)

Open Access This article is distributed under the terms of the Creative Commons Attribution License which permits any use, distribution, and reproduction in any medium, provided the original author(s) and the source are credited.

\section{References}

1. Patau, K., Smith, D. W., Therman, E., Inhorn, S. L., \& Wagner, H. P. (1960). Multiple congenital anomaly caused by extra chromosome. Lancet, 1, 790-793.

2. Carey, J. C. (2005). Trisomy 18 and 13 syndromes. In J. Allanson \& S. Cassidy (Eds.), Management of genetic syndromes (2nd ed., pp. 555-568). Hoboken, NJ: Wiley.

3. Jones, K. L. (2006). Trisomy 13 syndrome. In K. L. Jones (Ed.), Smith's recognized patterns of human malformation (6th ed., pp. 18-21). Philadelphia: Elsevier Saunders.

4. Goldstein, H., \& Nielsen, K. G. (1988). Rates and survival of individuals with trisomy 18 and 13. Clinical Genetics, 34, 366-372.

5. Wyllie, J. P., Wright, M. J., Burn, J., \& Hunter, S. (1994). Natural history of trisomy 13. Archives of Disease in Childhood, 71, 343-345.

6. Forrester, M. B., \& Merz, R. D. (1999). Trisomies 13 and 18: Prenatal diagnosis and epidemiologic studies in Hawaii, 1986-1997. Genetic Testing and Molecular Biomarkers, 3, 335-340

7. Root, S., \& Carey, J. C. (1994). Survival in trisomy 18. American Journal of Medical Genetics, 49, 170-174.
8. Rasmussen, S. A., Wong, L. Y. C., Yang, Q. Y., May, K. M., \& Freidman, J. M. (2003). Population-based analysis of mortality in trisomy 13 and trisomy 18. Pediatrics, 111, 777-784.

9. Norup, M. (1998). Attitudes towards abortion among physicians working at obstetrical and paediatric departments in Denmark. Prenatal Diagnosis, 18, 273-280.

10. Bos, A. P., Broers, C. J. M., Hazebroek, F. W. J., et al. (2003). Avoidance of emergency surgery in newborn infants with trisomy 18. Lancet, 339, 913-917.

11. Kosho, T., Nakamura, T., Kawame, H., Baba, A., Tamura, M., \& Fukushima, Y. (2006). Neonatal management of trisomy 18: Clinical details of 24 patients receiving intensive treatment. American Journal of Medical Genetics Part A, 140, 937-944.

12. Nishida, H., \& Sakamoto, S. (1992). Ethical problems in neonatal intensive care unit-medical decision making on the neonate with poor prognosis. Early Human Development, 29, 403-406.

13. Kosho, T. (2008). Invited comment: Care of children with trisomy 18 in Japan. American Journal of Medical Genetics, 146A, $1369-1371$

14. Imataka, G., Nitta, A., Suzumura, H., Watanabe, H., Yamanouchi, H., \& Arisaka, O. (2007). Survival of trisomy 18 cases in japan. Journal of Genetic Counseling, 18, 303-308.

15. Baty, B. J., Blackburn, B. L., \& Carey, J. C. (1994). Natural history of trisomy 18 and trisomy 13: Growth, physical assessment, medical histories, survival, and recurrence risk. American Journal of Medical Genetics, 49, 175-188.

16. Brewer, C. M., Holloway, S. H., Stone, D. H., Carothers, A. D., \& Fitzpatrick, D. R. (2002). Survival in trisomy 13 and trisomy 18 cases ascertained from population based registers. Journal of Medical Genetics, 39, e54.

17. Imataka, G., Yamanouchi, H., Tsuboi, T., Hagiwara, Y., \& Eguchi, M. (2000). Long survival case of trisomy 13. No to Hattatsu S159 [in Japanese].

18. Petit, P., \& Fryns, J. P. (1994). Normal/trisomy 13 mosaicism in a 38-year-old male. Journal of Genetic Counseling, 5, 311-314.

19. Lin, H. Y., Lin, S. P., Chen, Y. J., et al. (2007). Clinical characteristics and survival of trisomy 13 in a medical center in Taiwan, 1985-2004. Pediatrics International, 49, 380-386.

20. Graham, E. M., Bradley, S. M., Shirali, G. S., Hills, C. B., Atz, A. M., \& Pediatric Cardiac Care Consortium. (2004). Effectiveness of cardiac surgery in trisomy 13 and 18 (from the Pediatric Cardiac Care Consortium). American Journal of Cardiology, 93, 801-803.

21. Kaneko, Y., Kobayashi, J., Yamamoto, Y., et al. (2008). Intensive cardiac management in patients with trisomy 13 or trisomy 18 . American Journal of Medical Genetics, 146A, 1372-1380. 